Ciência Florestal, Santa Maria, v. 23, n. 1, p. 129-138, jan.-mar., 2013

ISSN 0103-9954

\title{
MANEJO DO SOLO E CRESCIMENTO INICIAL DE Eucalyptus grandis Hill ex Maiden EM ARGISSOLO ${ }^{1}$
}

\author{
SOIL TILLAGE AND INITIAL GROWTH OF Eucalyptus grandis Hill ex Maiden IN HAPLUDALF
}

Juliana Prevedello ${ }^{2}$ Douglas Rodrigo Kaiser ${ }^{3}$ Dalvan José Reinert ${ }^{4}$ Eduardo Saldanha Vogelmann ${ }^{5}$ Eracilda Fontanela ${ }^{6}$ José Miguel Reichert ${ }^{4}$

\section{RESUMO}

O cultivo de espécies florestais de rápido crescimento tem aumentado no Brasil, devido à diversificação do uso de sua madeira e adaptação edafoclimática. No setor florestal, a técnica do cultivo mínimo tem se destacado como forma de aumentar a produtividade, garantindo a manutenção da biodiversidade e a conservação do solo. O presente estudo foi realizado na área experimental da Fundação Estadual de Pesquisa Agropecuária - Centro de Pesquisa em Florestas em Santa Maria - RS, com o objetivo de avaliar o efeito dos métodos de preparo do solo na densidade, na resistência do solo à penetração e no desenvolvimento inicial das raízes e parte aérea do Eucalyptus grandis, em um Argissolo Vermelho-Amarelo Distrófico arênico com textura franco-arenosa. Foram comparados quatro manejos do solo: plantio direto, escarificado, escarificado mais grade niveladora e enxada rotativa, instalados em blocos ao acaso com três repetições. O solo sob plantio direto condicionou menor crescimento radicular e aéreo do eucalipto devido à maior resistência à penetração e densidade do solo, quando comparado aos preparos com mobilização. A análise da distribuição radicular no perfil, apesar de ser um método qualitativo, foi eficiente em demonstrar o efeito do preparo do solo para a implantação do Eucalyptus grandis. O preparo e a mobilização do solo resultaram em maior crescimento inicial de Eucalyptus grandis. Os efeitos da escarificação sobre as propriedades físicas do solo persistiram após um ano da mobilização do solo.

Palavras-chave: florestas plantadas; resistência do solo à penetração; compactação do solo.

\section{ABSTRACT}

The forest species cultivation with rapid growth in Brazil has increased, mainly due to the diverse use of its wood and climate adaptation. The cultivation with minimum tillage in the forest sector stands out a way to increase productivity, combined with the maintenance of biodiversity and soil conservation. This study was conducted at the experimental area of State Foundation for Agricultural Research - Research Center for Forestry in Santa Maria - RS, with aimed to evaluate the effect of the soil tillage methods on soil physical properties and on initial development of Eucalyptus grandis, in a sandy loam Typic Hapludalf. Four soil management practices were compared: no-tillage; chisel tillage; chisel tillage plus harrowing and; rotary tillage (rotary tiller), installed in a randomized block design with three replications. The soil under no-tillage conditioned lower initial growth of eucalyptus due higher soil penetration resistance and bulk density, when compared with treatments with mobilization. The root distribution analysis in soil, despite being a qualitative method, was effective in demonstrating the effect of soil tillage for the Eucalyptus grandis

1. Parte da dissertação de mestrado do primeiro autor.

2. Engenheira Florestal, Dri ${ }^{\mathrm{a}}$, Pós-Doutoranda em Engenharia Florestal, Centro de Ciências Rurais, Universidade Federal de Santa Maria, Av. Roraima, 1000, CEP 97105-900, Santa Maria (RS). Bolsista Fapergs/Capes. juliprevedello@gmail.com

3. Engenheiro Agrônomo, Dr., Professor do Curso de Agronomia, Universidade Federal da Fronteira Sul - Campus Cerro, CEP 97900-000, Cerro Largo (RS).douglasrodrigokaiser@gmail.com

4. Engenheiro Agrônomo, Dr., Professor do Departamento de Solos, Centro de Ciências Rurais, Universidade Federal de Santa Maria, Av. Roraima, 1000, CEP 97105-900, Santa Maria (RS). dalvanreinert@gmail.com

5. Engenheiro Agrônomo, Msc., Doutorando em Ciência do Solo, Centro de Ciências Rurais, Universidade Federal de Santa Maria, Av. Roraima, 1000, CEP 97105-900, Santa Maria (RS). Bolsista Capes. eduardovogelmann@hotmail.com

6. Engenheira Agrícola, Dra, Instituto Federal do Rio Grande do Sul, Rua Nelsi Ribas Fritsch, 1111, CEP 98200-000, Ibirubá (RS). efontanela@gmail.com

Recebido para publicação em 14/10/2010 e aceito em 1/11/2011 
plantation. The soil tillage with mobilization resulted in a higher initial growth of Eucalyptus grandis. The chisel tillage effects in the soil physical properties persisted after one year of soil tillage.

Keywords: planted forest; soil penetration resistance; soil compaction.

\section{INTRODUÇÃO}

O cultivo de espécies florestais de rápido crescimento tem aumentado no Brasil, devido à diversificação do uso de sua madeira e pela facilidade de adaptação às diferentes condições edafoclimáticas. Além disso, essas espécies contribuem significativamente no sequestro de carbono, auxiliando na melhoria da qualidade do ar (PAIXÃO et al., 2006). Atualmente, o Brasil apresenta a maior área de floresta plantada da América Latina, com cerca de 5,74 milhões de hectares, destes, 61,8 \% são cultivados com espécies de eucalipto (SBS, 2008).

Os ecossistemas destinados às plantações florestais são, geralmente, de baixa fertilidade natural ou áreas com histórico de uso inadequado da terra, com desmatamento e emprego de técnicas impróprias de manejo agropecuário (GONÇALVES, 2002). Para o adequado estabelecimento das espécies florestais, é necessário que o solo permita o crescimento das raízes, o fornecimento de água e nutrientes e as trocas gasosas (CLEMENTE et al., 2005). Essas condições são atendidas quando o solo apresenta baixa resistência à penetração e grande quantidade de poros. No setor florestal, a técnica do cultivo mínimo tem se destacado como forma de aumentar a produtividade, garantindo a manutenção da biodiversidade e a conservação do solo (GONÇALVES, 2002). Porém, o tráfego de máquinas, quando realizado de forma intensa e inadequada, altera a estrutura do solo, modificando as condições do ambiente radicular das culturas, podendo causar a compactação (REICHERT et al., 2009b), refletindo no aumento da densidade, aumento da resistência à penetração das raízes e redução da porosidade, o que dificulta o estabelecimento e desenvolvimento do sistema radicular das plantas (BENGHOUGH et al., 2006). Além disso, as características do solo e a disponibilidade de água também afetam a qualidade da madeira e da celulose produzida (GAVA et al., 2008).

A qualidade física do solo pode ser avaliada em função da habilidade das raízes em penetrarem no perfil, a qual diminui quando a densidade e a resistência do solo aumentam (REICHERT et al., 2007). Além disso, o baixo conteúdo de água aumenta a coesão entre as partículas do solo, dificultando a penetração no perfil de solo, pois a resistência oferecida pelo mesmo é superior à força impressa pela raiz na região meristemática e na coifa (HAMZA e ANDERSON, 2005). Diversos autores têm demonstrado que o valor de 2,0 MPa é restritivo ao crescimento radicular das culturas agrícolas (TAYLOR et al., 1966; TORMENA et al., 2002). Porém, as raízes de eucalipto são mais tolerantes a valores elevados de resistência à penetração (MISRA e GIBBONS, 1996) e, dessa forma, o seu crescimento pode ser afetado com valores de resistência maiores que os observados para culturas agrícolas (REICHERT et al., 2009b).

O crescimento das raízes, o desenvolvimento e a produção das culturas são influenciados pelo nível de compactação do solo, que depende do sistema de manejo. Assim, esse trabalho tem por objetivo quantificar o efeito dos métodos de manejo do solo na densidade, na resistência do solo à penetração e no desenvolvimento inicial das raízes e da parte aérea de Eucalyptus grandis em um Argissolo com textura franco-arenosa.

\section{MATERIAL E MÉTODOS}

O experimento foi conduzido na área experimental pertencente à Fundação Estadual de Pesquisa Agropecuária - Centro de Pesquisas em Florestas, no município de Santa Maria - RS. O clima da região, segundo a classificação de Köppen, é do tipo Cfa, subtropical úmido, sem estiagens. A precipitação média anual é de $1.769 \mathrm{~mm}$ e a temperatura média anual é de $19^{\circ} \mathrm{C}$ (MORENO, 1961). O solo é classificado como Argissolo Vermelho-Amarelo Distrófico arênico (EMBRAPA, 2006) e possui valores médios de $165,5 \mathrm{~g} \mathrm{~kg}^{-1} \mathrm{de}$ argila, 195,7 $\mathrm{g} \mathrm{kg}^{-1}$ de silte e $638,7 \mathrm{~g} \mathrm{~kg}^{-1}$ de areia (classe textural franco- arenosa) até a profundidade de $0,30 \mathrm{~m}$. $\mathrm{O}$ solo da área não apresenta horizonte $\mathrm{E}$ e o horizonte Bt inicia a $0,80 \mathrm{~m}$ de profundidade e apresenta $300 \mathrm{~g} \mathrm{~kg}^{-1}$ de argila. Antes da instalação do experimento a área experimental encontrava-se em pousio por mais de 20 anos, com cobertura de gramíneas nativas. 
O delineamento experimental utilizado foi de blocos ao acaso, com os seguintes tratamentos: plantio direto (PD), escarificação até $0,30 \mathrm{~m}$ de profundidade (Esc), escarificação até $0,30 \mathrm{~m}$ de profundidade mais grade niveladora $(E G)$ e enxada rotativa até $0,20 \mathrm{~m}$ deprofundidade (ER), distribuídos em três blocos com parcelas de 20 x 30 metros. A escarificação foi realizada com escarificador de uma haste, aplicado na linha de plantio. Os preparos do solo foram realizados no dia 21/11/2006 com plantio das mudas de Eucalyptus grandis no dia 28/11/2006, com espaçamento de 2,0 x 3,0 m. Cada parcela foi composta por 100 plantas, distribuídas em 10 linhas com 10 plantas. No plantio direto foi aplicado herbicida dessecante (glifosato) na linha de plantio, numa faixa de 1 metro de largura, com posterior transplante das mudas em covas de $0,10 \mathrm{~m}$ de profundidade e $0,08 \mathrm{~m}$ de diâmetro. As manutenções da área foram constituídas de roçadas e contínuo combate às formigas.

As avaliações do crescimento em altura e diâmetro a altura do peito (Dap) foram realizadas nas 36 plantas centrais de cada parcela, com o auxílio de uma régua telescópica e paquímetro digital, aos 12 meses de idade das plantas. Aos 8 meses após o plantio, selecionou-se uma planta representativa de cada parcela para avaliar a distribuição do sistema radicular, usando o método do perfil, descrito por Böhm (1979). O perfil foi feito perpendicularmente à linha de plantio, com a parede vertical distante $0,05 \mathrm{~m}$ da planta. Após a exposição das raízes, com auxílio de varetas de metal, utilizou-se um retângulo de $1,00 \times 0,60 \mathrm{~m}$ subdividido com fio de nylon, formando uma malha de $0,05 \times 0,05 \mathrm{~m}$ para desenhar as raízes no perfil.

As amostragens de solo foram realizadas em três épocas distintas: época 1, antes da aplicação dos tratamentos, com o objetivo de caracterizar a área experimental; época 2, três meses após instalação do experimento; época 3, doze meses após a instalação. Amostras de solo com estrutura preservada foram coletadas em cilindros metálicos de $0,06 \mathrm{~m}$ de diâmetro e $0,05 \mathrm{~m}$ de altura nas camadas de solo de $0,00-0,10 ; 0,10-0,20$ e $0,20-0,30 \mathrm{~m}$, para determinar a densidade do solo, segundo metodologia descrita em EMBRAPA (1997).

A resistência mecânica do solo à penetração (RP) foi determinada com o auxílio de um penetrômetro digital com armazenamento eletrônico dos dados, possuindo ponta cônica com ângulo de penetração de $30^{\circ}$. As leituras foram realizadas em pontos perpendiculares à linha de plantio, equidistantes a cada $0,20 \mathrm{~m}$ até $0,60 \mathrm{~m}$, em ambas as direções. Nesses pontos, as leituras foram realizadas a cada $0,015 \mathrm{~m}$ de profundidade até $0,60 \mathrm{~m}$. A partir dessas informações, confeccionouse um mapa da distribuição da resistência no perfil. Para a quantificação da umidade gravimétrica $(\mathrm{Ug})$, concomitantemente às medidas de RP, foram coletadas amostras de solo, com trado calador, nas camadas de $0,00-0,10 ; 0,10-0,20 ; 0,20-0,30 ; 0,30$ 0,$40 ; 0,40-0,50$ e $0,50-0,60 \mathrm{~m}$. Os dados de Ug foram transformados em umidade volumétrica $(\theta \mathrm{v})$; pela relação $\theta \mathrm{v}=\mathrm{Ug} \times \mathrm{Ds}$. A RP foi avaliada aos três meses (época 2) e aos doze meses (época 3 ) após a instalação do experimento. Um modelo não linear (BUSSCHER, 1990) foi obtido relacionando a RP, densidade do solo e umidade volumétrica, para as camadas $0,00-0,10 ; 0,10-0,20 ; 0,20-0,30 \mathrm{~m}$, pelo método PROC NLIN (SAS INSTITUTE, 2002).

Os resultados obtidos para densidade do solo, resistência à penetração e crescimento do eucalipto foram submetidos à análise de variância. Para a comparação entre as médias dos tratamentos utilizou-se o teste de Tukey ao nível de $5 \%$ de significância. $\mathrm{Na}$ análise dos dados de densidade, considerou-se o sistema de manejo como fator principal e a época de avaliação como fator secundário, constituindo-se um modelo de análise com parcela subdividida, com o uso do software SAS (SAS INSTITUTE, 2002).

\section{RESULTADOS E DISCUSSÃO}

Antes de efetuar os diferentes manejos do solo (época 1), a densidade não apresentou diferença significativa nas camadas avaliadas, o que demonstra ser uma área homogênea quanto ao estado estrutural. Houve interação significativa para a densidade do solo entre preparo e época de avaliação nas camadas de 0,00-0,10 e 0,20-0,30 m (Tabela 1), com redução na densidade após o preparo (épocas 2 e 3). Após um ano da aplicação ainda foi observado o efeito do manejo sobre a densidade, principalmente no Esc e ER, o que corrobora com a afirmação de Pierce et al. (1992) de que o efeito da escarificação pode persistir por anos em solos de textura franco-arenosa.

A densidade do solo foi menor na camada superficial $(0,00-0,10 \mathrm{~m})$, provavelmente em função da mobilização e incorporação dos resíduos vegetais pelos implementos utilizados durante o preparo do solo, os quais favorecem a atividade biológica e reduzem a ação do peso das máquinas. Além disso, 
TABELA 1: Densidade do solo para os diferentes manejos e épocas de amostragem, nas camadas 0,000,10; 0,10-0,20; 0,20-0,30 m do Argissolo.

TABLE 1: Soil bulk density for different tillage and sampling times in the layers of $0.00-0.10 ; 0.10-0.20$; $0.20-0.30 \mathrm{~m}$ in the Hapludalf soil.

\begin{tabular}{|c|c|c|c|c|c|}
\hline \multicolumn{6}{|c|}{ Manejo do solo } \\
\hline Época & PD & Esc & EG & ER & Média \\
\hline \multicolumn{6}{|c|}{ Densidade do solo $\left(\mathrm{Mg} \mathrm{m}^{-3}\right)$} \\
\hline \multicolumn{6}{|c|}{ Camada de $0,00-0,10 \mathrm{~m}$} \\
\hline 1 & $1,52 \mathrm{Aa}$ & $1,48 \mathrm{Aa}$ & $1,43 \mathrm{Aa}$ & $1,45 \mathrm{Aa}$ & 1,47 \\
\hline 2 & $1,50 \mathrm{Aa}$ & 1,29ABab & $1,26 \mathrm{Aab}$ & $1,12 \mathrm{Bb}$ & 1,29 \\
\hline 3 & $1,50 \mathrm{Ba}$ & $1,30 \mathrm{Ba}$ & $1,29 \mathrm{Aa}$ & $1,15 \mathrm{Ba}$ & 1,20 \\
\hline Média & 1,40 & 1,32 & 1,33 & 1,24 & \\
\hline CV (\%) & & & & & 6,84 \\
\hline \multicolumn{6}{|c|}{ Camada de $0,10-0,20 \mathrm{~m}$} \\
\hline 1 & 1,57 & 1,56 & 1,53 & 1,53 & $1,55 \mathrm{a}$ \\
\hline 2 & 1,58 & 1,37 & 1,32 & 1,52 & $1,45 \mathrm{a}$ \\
\hline 3 & 1,50 & 1,39 & 1,40 & 1,50 & $1,45 \mathrm{a}$ \\
\hline Média & $1,55 \mathrm{a}$ & $1,44 \mathrm{a}$ & $1,42 \mathrm{a}$ & $1,52 \mathrm{a}$ & \\
\hline CV (\%) & & & & & 7,73 \\
\hline \multicolumn{6}{|c|}{ Camada de $0,20-0,30 \mathrm{~m}$} \\
\hline 1 & $1,52 \mathrm{Aa}$ & $1,54 \mathrm{Aa}$ & $1,50 \mathrm{Aa}$ & $1,48 \mathrm{Aa}$ & 1,51 \\
\hline 2 & $1,57 \mathrm{Aa}$ & $1,24 \mathrm{Bb}$ & $1,35 \mathrm{Aab}$ & $1,52 \mathrm{Aa}$ & 1,42 \\
\hline 3 & $1,49 \mathrm{Aa}$ & $1,47 \mathrm{Aa}$ & $1,42 \mathrm{Aa}$ & $1,46 \mathrm{Aa}$ & 1,46 \\
\hline Média & 1,53 & 1,42 & 1,42 & 1,49 & \\
\hline $\mathrm{CV}(\%)$ & & & & & 5,88 \\
\hline
\end{tabular}

Em que: médias seguidas de letras iguais, maiúscula na coluna e minúscula na linha, não diferem estatisticamente entre si pelo Teste de Tukey a $5 \%$ de significância. Época $1=$ antes do preparo; Época $2=$ três meses após o preparo e Época 3 = doze meses após o preparo. $\mathrm{PD}$ = Plantio direto; Esc = escarificação; EG= escarificação e gradagem e ER = enxada rotativa. $\mathrm{CV}(\%)=$ coeficiente de variação em porcentagem.

a maior frequência dos processos de umedecimento e secagem na superfície facilita a recuperação da estrutura nesta camada (CAVICHIOLO, 2005). O maior valor de densidade ocorreu no $\mathrm{PD}$, em todas as camadas avaliadas, o que representa a condição estrutural natural desse solo. Houve aumento da densidade com a profundidade e, conforme relata Suzuki (2005), essa situação decorre devido à acomodação das partículas de solo e da carga exercida pelas camadas superiores. Porém, esses valores de densidade estão abaixo da faixa de 1,7 a $1,8 \mathrm{Mg} \mathrm{m}^{-3}$, considerada como restritiva para o crescimento radicular de culturas anuais em solo arenoso (REICHERT et al., 2007).

A resistência do solo à penetração integra os efeitosda densidadee daumidade nas condições físicas do solo necessárias para o crescimento das raízes (TORMENA et al., 2002). A RP na época 2 (Figura 1) evidenciou a ação dos diferentes implementos bem como a profundidade atingida no momento do preparo do solo. O PD, Esc e EG apresentaram valores máximos de RP na profundidade de $0,40 \mathrm{~m}$, sendo respectivamente de 1,69, 1,80 e 1,65 $\mathrm{MPa}$. No tratamento ER, o máximo valor de RP encontrado foi de 1,79 MPa na profundidade de 0,20 m. Martins et al. (2002) relatam que a resistência à penetração aumenta a partir dos $0,15 \mathrm{~m}$ de profundidade, devido aos implementos não atingirem as camadas mais profundas do solo no momento do preparo, além de sofrer maior efeito do tráfego de máquinas. Nas condições de umidade no momento da avaliação, nenhum dos tratamentos superou o limite de $2 \mathrm{MPa}$ de RP, considerado por Taylor et al. (1966) como crítico ao desenvolvimento radicular das plantas. Na época 3 (Figura 2), a RP sofreu decréscimo em todos os tratamentos avaliados em função do maior conteúdo de umidade do solo durante a avaliação, o que evidencia a correlação negativa entre umidade e resistência do solo à penetração (COLLARES et al., 2006; REICHERT et al., 2007).

$\mathrm{O}$ efeito acumulativo de pressões de máquinas e implementos que o solo recebe e, ainda, a acumulação natural das partículas podem ter sido responsáveis pelo aumento da RP em profundidade, 
verificados nas épocas 2 e 3 , principalmente a partir de 0,16 m. Em contrapartida, os tratamentos que receberam mobilização resultaram em redução da RP, concordando com os dados obtidos por Tormena et al. (2002), pois o revolvimento parcial do solo, especialmente nas camadas superficiais, além da adição de resíduos vegetais e incremento
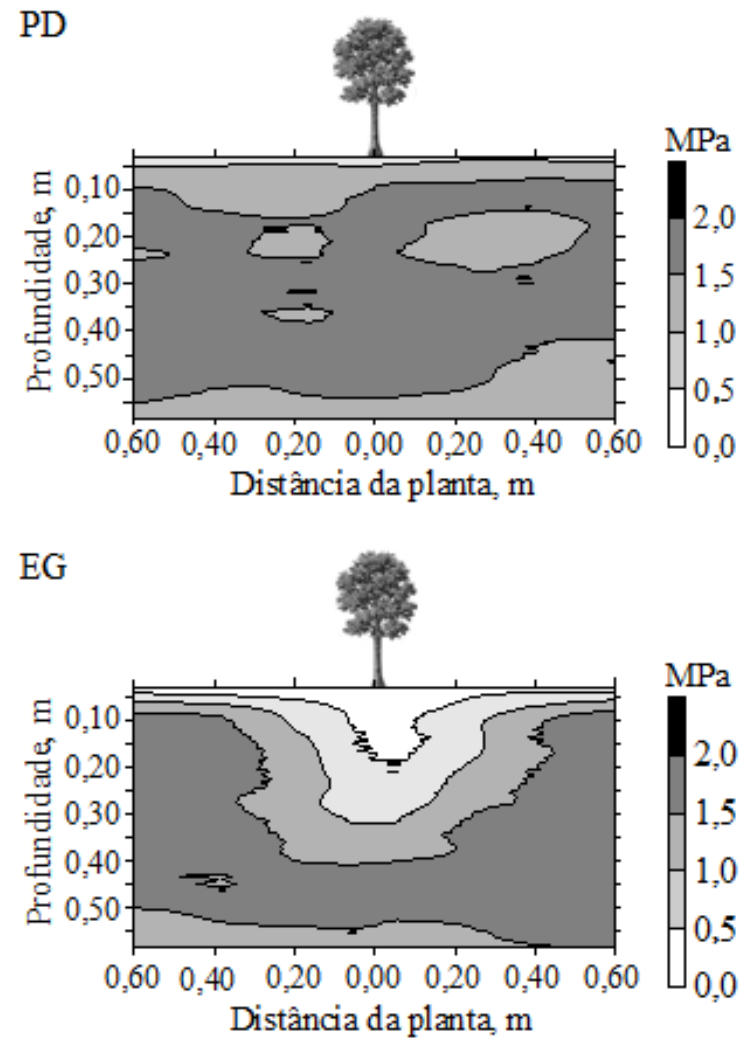

(a)

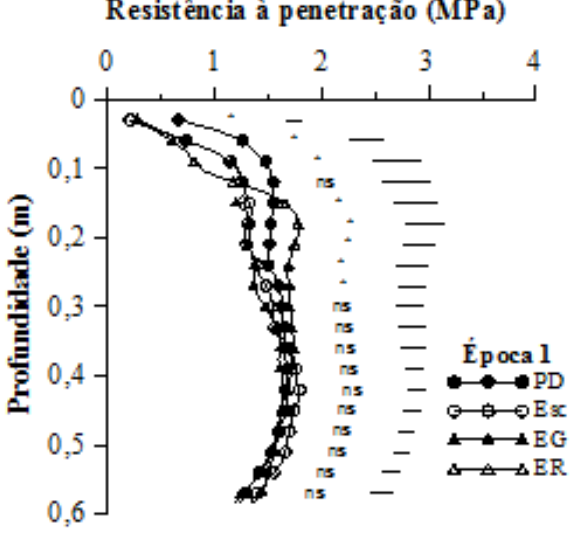

de material orgânico, favorecem a estruturação do solo em superfície. Levando-se em consideração a redução da densidade e RP, o ER mostrou-se mais eficiente que os tratamentos escarificados em relação ao PD, na camada de $0,00-0,10 \mathrm{~m}$. Porém, o maior revolvimento pode resultar em prejuízos para a conservação das características do solo, pois favorece
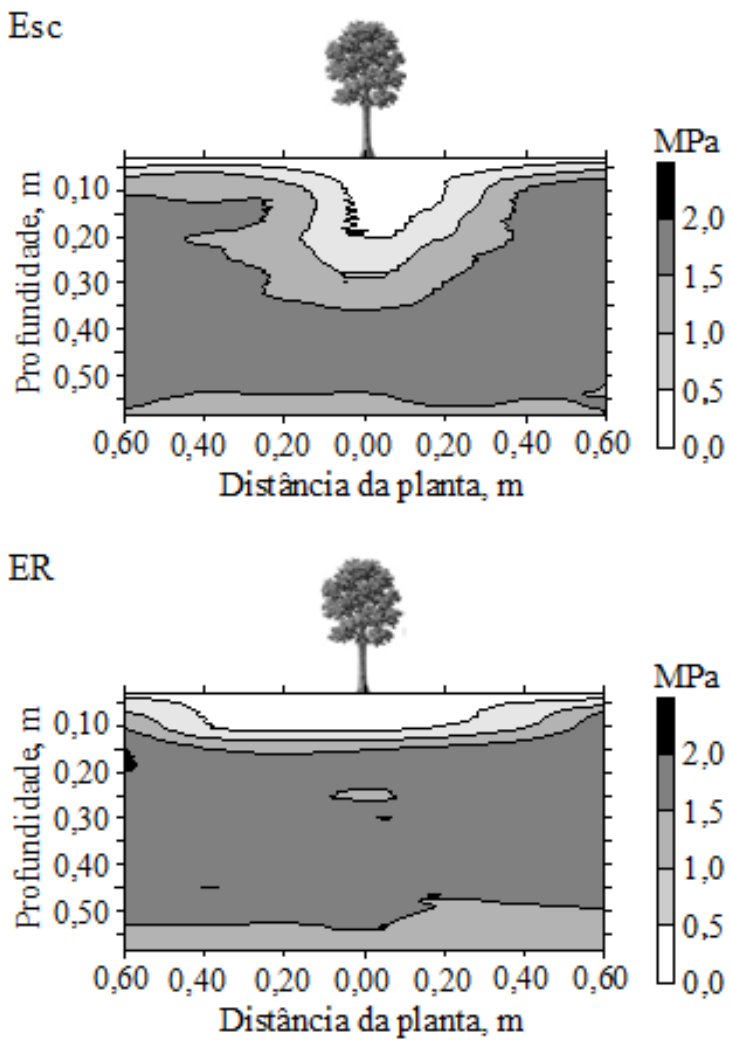

(b)

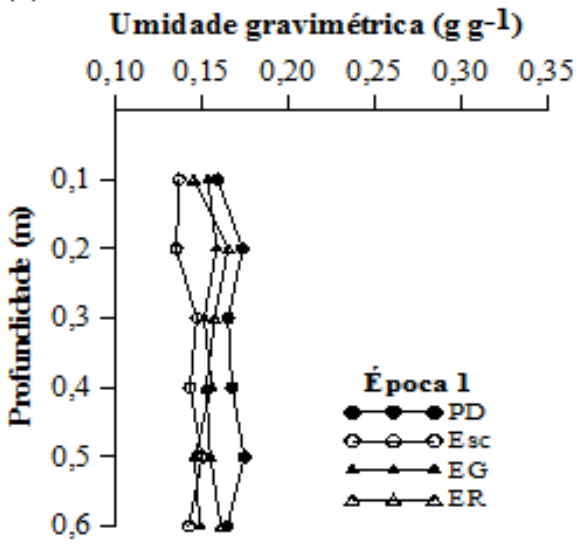

FIGURA 1: Resistência do solo à penetração na época 2 (aos 3 meses de idade), para o plantio direto (PD), escarificado (Esc), Escarificação + grade niveladora (EG), enxada rotativa (ER). (a) Média de resistência à penetração dos pontos de amostragens e (b) umidade do solo no momento da avaliação. $*$ = significância a $5 \%$ de probabilidade de erro e ns = não significativo.

FIGURE 1: Soil penetration resistance at the times 2 (at 3 months after planting) for the no-tillage (PD), chisel tillage (Esc), chisel tillage plus harrowing (EG), rotary tillage (ER). (a) mean of penetration resistance in different sampling sites and (b) soil moisture at the time of evaluation. $*=$ significance at $5 \%$ probability of error and $n s=$ not significant. 
a maior incorporação e decomposição dos resíduos vegetais reduzindo a quantidade de cobertura, importantes para o controle da erosão e das perdas de água do solo (TORMENA et al., 2002), podendo resultar em maior vulnerabilidade das culturas às condições climáticas neste sistema de preparo.
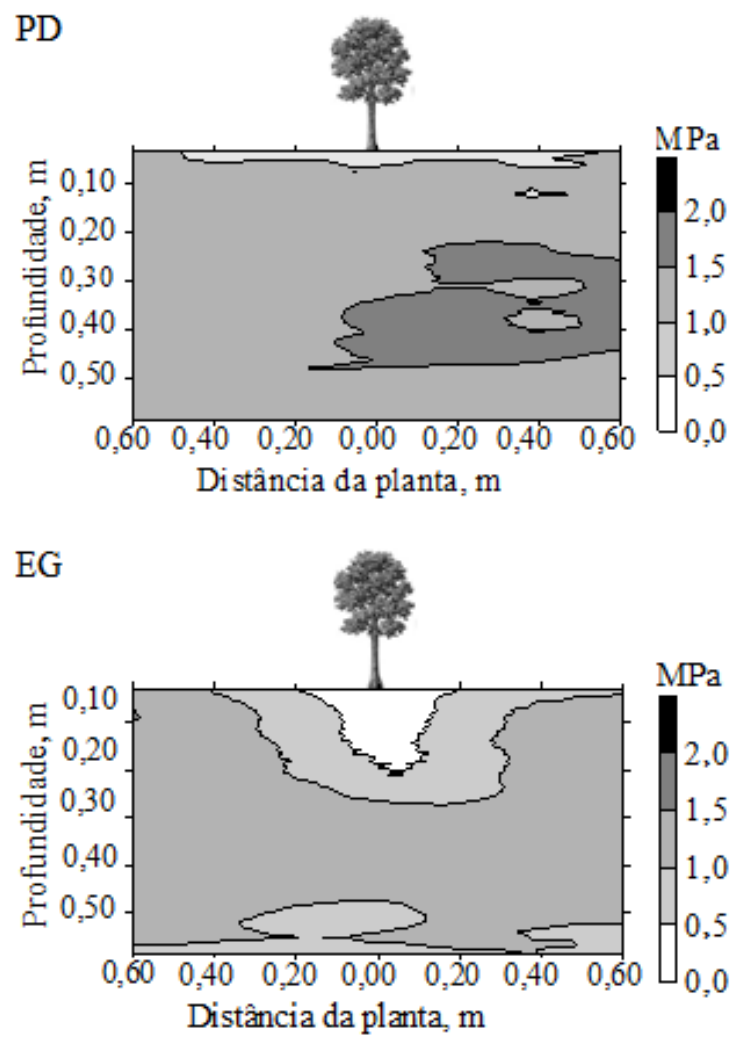

(a)

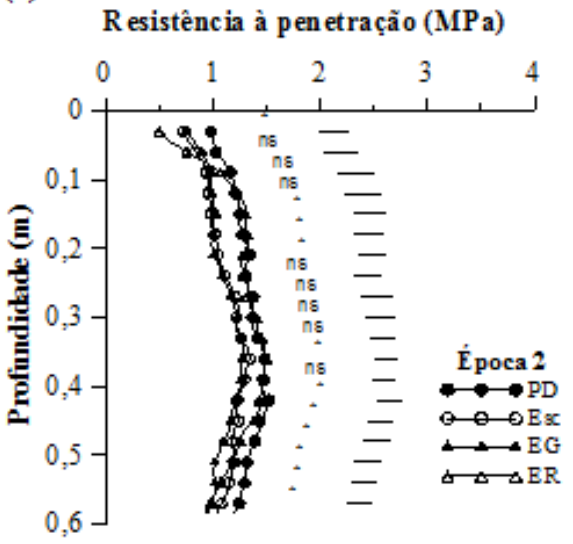

A equação não linear obtida relacionando os dados de RP, Ds e $\theta \mathrm{v}$, nas camadas de 0,000,$10 ; 0,10-0,20$ e $0,20-0,30 \mathrm{~m}$ para a época 2 (Figura 3a) foi: $\mathrm{RP}=0,6654 \times \mathrm{v}^{-0,0610} \times \mathrm{Ds}^{1,4731}$, $\mathrm{R}^{2}=0,89(\mathrm{p}<0,0001)$ e para época 3 (Figura 3b) foi: $\mathrm{RP}=0,4008 \times \theta \mathrm{v}^{-0,4748} \times \mathrm{Ds}^{1,2179}, \mathrm{R}^{2}=$
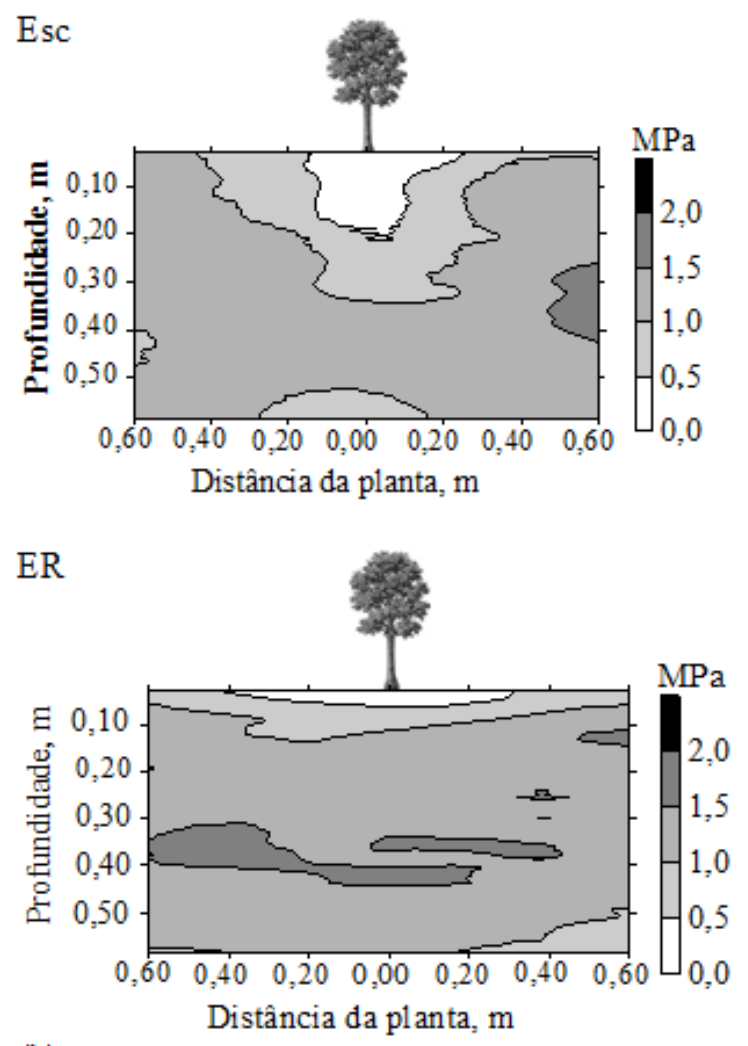

(b)

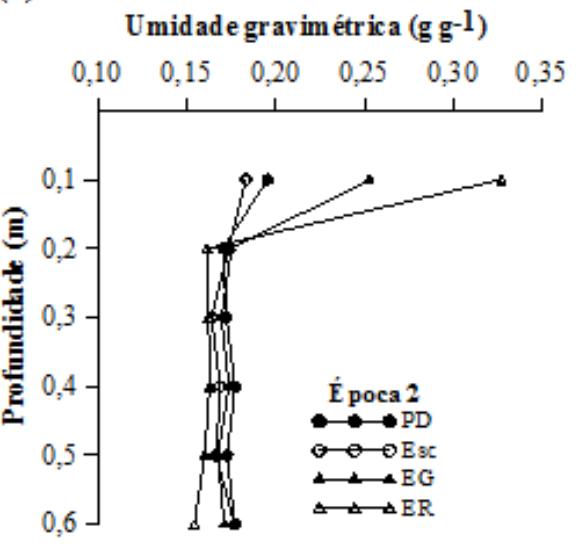

FIGURA 2: Resistência do solo à penetração na época 3 (aos 12 meses de idade), para o plantio direto (PD), escarificado (Esc), Escarificação + grade niveladora (EG), enxada rotativa (ER). (a) Média de resistência à penetração dos pontos de amostragens e (b) umidade do solo no momento da avaliação. * = significância a $5 \%$ de probabilidade de erro e ns = não significativo.

FIGURE 2: Soil penetration resistance at the times 3 (at 12 months after planting) for the no-tillage (PD), chisel tillage (Esc), chisel tillage plus harrowing (EG), rotary tillage (ER). (a) Mean of penetration resistance in different sampling sites and (b) soil moisture at the time of evaluation. $*=$ significance at $5 \%$ probability of error and ns $=$ not significant. 
(a)

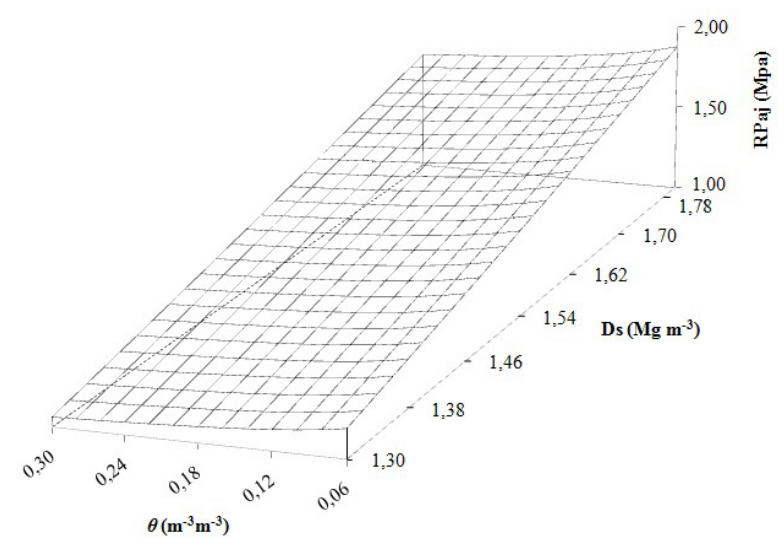

(b)

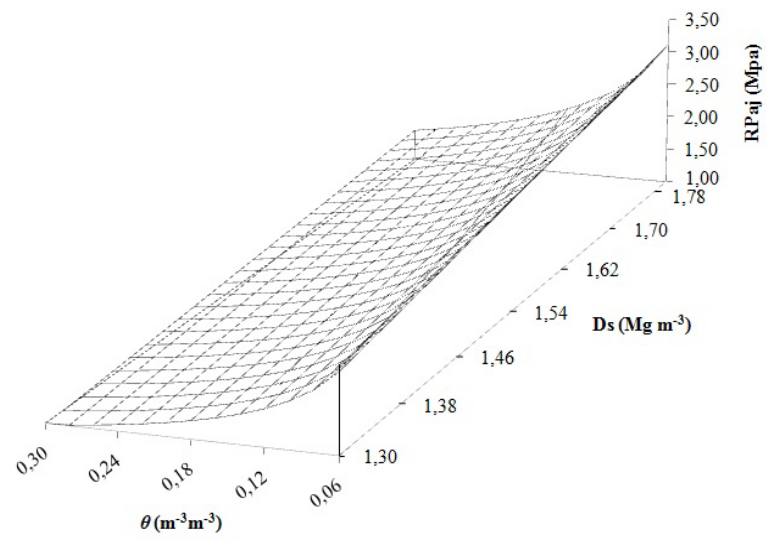

FIGURA 3: Resistência à penetração ajustada (RPaj) pelo modelo de Busscher (1990) em função da umidade volumétrica $(\theta \mathrm{v})$ e da densidade do solo (Ds) para a época 2 (a) e época 3 (b).

FIGURE 3: Penetration resistance set (RPaj) by Busscher's model (1990) as a function of volumetric water content $(\theta)$ and bulk density (Ds) for the time 2 (a) and time 3 (b).

$0,85(\mathrm{p}<0,0001)$. A partir dos resultados do ajuste do modelo, pode-se inferir que houve relação negativa entre RP e $\theta \mathrm{v}$ para as duas épocas avaliadas, o que concorda com Silva et al. (2002), Lima et al. (2007) e Reichert et al. (2009a), para o mesmo tipo de solo e diferentes sistemas de preparo. Verificou-se relação positiva entre Ds e RP, corroborando com o encontrado por Gerard et al. (1982), Prado et al. (2002) e Lampurlanés e Cantero-Martínez (2003), em diferentes tipos de solos e sistemas de preparo. A elevação da densidade do solo pode provocar um rearranjamento e acomodamento das partículas do solo, com consequente redução da porosidade e aumento da resistência à penetração (SILVA et al., 2002).

As raízes do eucalipto são mais tolerantes a valores maiores de resistência à penetração do que plantas anuais (MISRA e GIBBONS, 1996). Esses autores observaram que, com um aumento da RP de 0,4 para 4,2 $\mathrm{MPa}$, houve redução no comprimento das raízes primárias e laterais de eucalipto de 71 para $31 \%$. Entretanto, Whitman et al. (1997) verificaram que RP superior a 1,0 MPa prejudicou o desenvolvimento de mudas de Eucalyptus grandis. Taylor et al. (1966) verificaram que valores de resistência à penetração de $2 \mathrm{MPa}$ resultou em limitações ao crescimento radicular de culturas agrícolas e com RP igual a 2,5 $\mathrm{MPa}$ o crescimento foi nulo. Entretanto, não foram verificados valores de RP acima de 1,9 MPa, dessa forma, as raízes não encontraram restrições ao crescimento nos intervalos de umidade e densidade do solo avaliados.

$\mathrm{O}$ maior volume de solo explorado pelas raízes do Eucalyptus grandis foi observado nos tratamentos revolvidos (Figura 4), onde se percebeu o crescimento preferencial e mais vigoroso em função da área preparada, menor densidade do solo e RP. Essa tendência também foi encontrada por Stape et al. (2002), que verificaram maior aprofundamento e densidade de raízes quanto maior o revolvimento do solo. Essa é uma característica desejável para o adequado estabelecimento do eucalipto, pois permite que as plantas explorem um maior volume de solo, aumentando o acesso à água e nutrientes, além de reduzir os efeitos negativos das estiagens, incrementando a resistência e vigor das plantas ao ataque de pragas e doenças.

A sobrevivência e crescimento em Dap, com reflexos na área basal e no volume, aumentaram à medida que se intensificou o preparo do solo. Isso pode estar relacionado com o maior desenvolvimento radicular, o qual pode ter favorecido para uma maior absorção de água e de nutrientes pelas plantas (Tabela 2). O Eucalyptus grandis plantado em solo sob preparo Esc, EG e ER apresentou, após 12 meses de plantio, um incremento em altura e Dap de, respectivamente, 20, 24 e $42 \%$, em relação ao $\mathrm{PD}$, evidenciando a importância do revolvimento do solo no início do desenvolvimento das mudas. Finger et al. (1996) encontraram um incremento em Dap $50 \%$ superior em solo subsolado em relação ao não subsolado, em povoamento com mais de 24 meses de idade. Maluf (1991) também constatou que preparos mais intensivos do solo favoreceram o crescimento inicial, principalmente pela menor infestação de ervas daninhas. 
PD

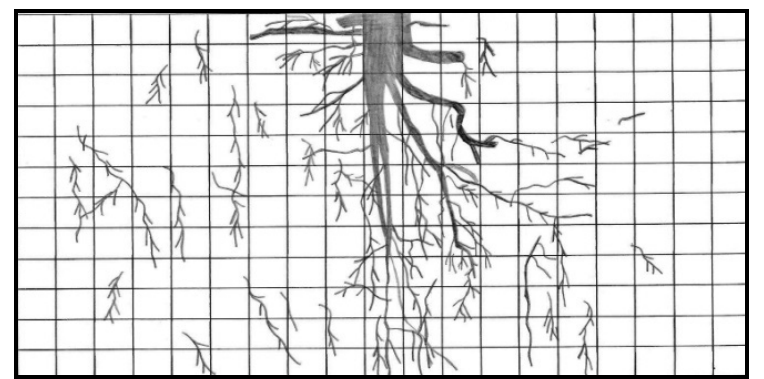

$\mathrm{EG}$

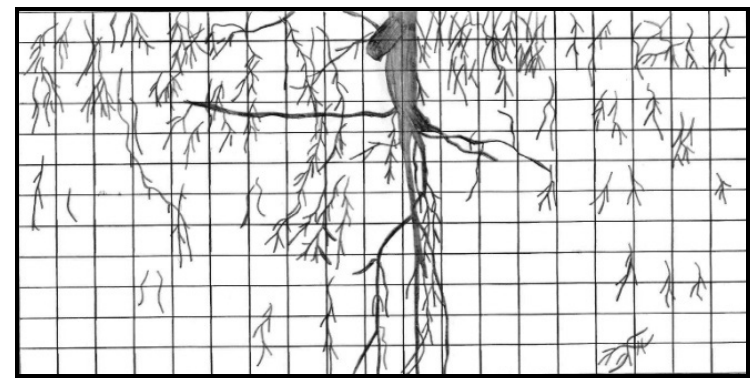

Esc

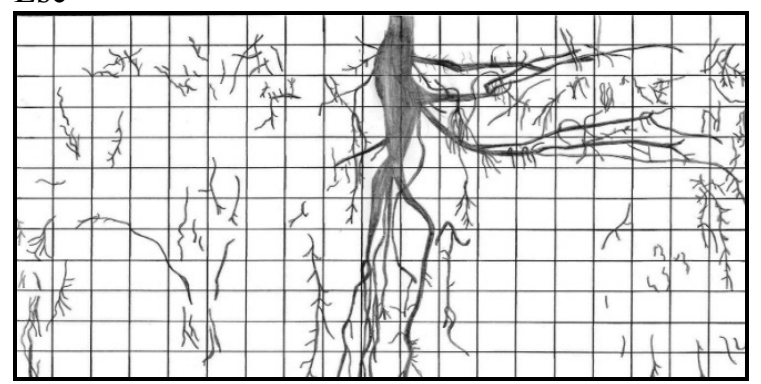

ER

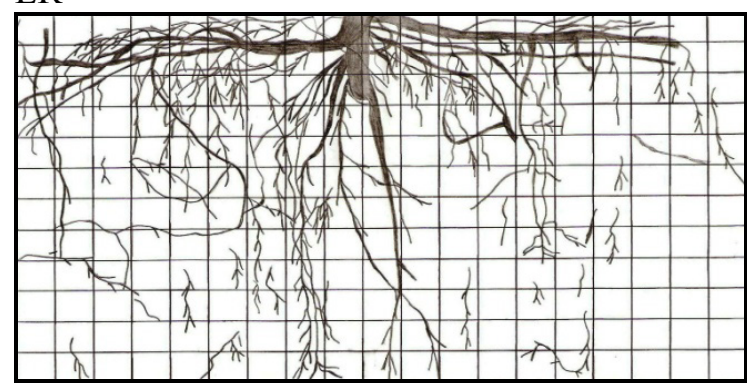

FIGURA 4: Distribuição radicular do Eucalyptus grandis no perfil do solo $(1,0$ x $0,60 \mathrm{~m})$ nos diferentes manejos. Avaliação realizada aos 8 meses após o plantio. Quadrícula com malha de $0,05 \mathrm{x}$ $0,05 \mathrm{~m}$.

FIGURE 4: Root distribution of Eucalyptus grandis in the soil profile $(1.0 \times 0.60 \mathrm{~m})$ in different tillages. Assessment at 8 months after planting. Square mesh of $0.05 \times 0.05 \mathrm{~m}$.

TABELA 2: Valores médios de diâmetro à altura do peito (Dap), altura, área basal, volume e porcentagem de sobrevivência do Eucalyptus grandis aos 12 meses de idade, nos diferentes manejos.

TABLE 2: Diameter at breast height (DBH), height total, basal area, volume and survival percentage of Eucalyptus grandis at 12 months after planting, for different tillages.

\begin{tabular}{cccccc}
\hline Manejo & Dap $(\mathrm{cm})$ & Altura $(\mathrm{m})$ & Área Basal $\left(\mathrm{m}^{2} \mathrm{ha}^{-1}\right)$ & Volume $\left(\mathrm{m}^{3} \mathrm{ha}^{-1}\right)$ & Sobrevivência $(\%)$ \\
\hline PD & $1,57 \mathrm{a}$ & $2,40 \mathrm{a}$ & $0,31 \mathrm{a}$ & $1,07 \mathrm{a}$ & $59 \mathrm{a}$ \\
Esc & $1,95 \mathrm{ab}$ & $2,65 \mathrm{a}$ & $0,59 \mathrm{~b}$ & $1,99 \mathrm{ab}$ & $82 \mathrm{ab}$ \\
EG & $2,06 \mathrm{ab}$ & $2,80 \mathrm{a}$ & $0,65 \mathrm{~b}$ & $2,23 \mathrm{ab}$ & $87 \mathrm{ab}$ \\
ER & $2,69 \mathrm{~b}$ & $3,58 \mathrm{~b}$ & $1,09 \mathrm{c}$ & $4,76 \mathrm{~b}$ & $91 \mathrm{c}$ \\
\hline
\end{tabular}

Em que: médias seguidas de letras iguais, na coluna, não diferem estatisticamente entre si pelo Teste de Tukey a $5 \%$ de probabilidade de erro. $\mathrm{PD}$ = Plantio direto; Esc = escarificação; $\mathrm{EG}=$ escarificação e gradagem e $\mathrm{ER}=$ enxada rotativa.

O solo manejado sob PD apresentou os maiores valores de Ds e RP o que resultou em restrições ao crescimento radicular e aéreo do eucalipto, mesmo apresentando valores não restritivos de Ds e RP para o crescimento do eucalipto conforme descrito por Taylor et al. (1966) e Reichert et al. (2007), respectivamente. O ER, mesmo revolvendo somente as camadas mais superficiais do solo, favoreceu o melhor desenvolvimento e crescimento das plantas de eucalipto, inclusive quando comparado com os tratamentos escarificados que promovem o revolvimento do solo em maiores profundidades. Essas características adquiridas pelo solo após a aplicação do manejo refletiram-se no índice de sobrevivência das plantas, onde o PD resultou em $59 \%$. Esse fato pode estar relacionado à maior dificuldade de estabelecimento das raízes do eucalipto no perfil do solo e, consequentemente, ao crescimento inicial mais lento, além de maior competição com a vegetação espontânea (MALUF, 1991; DEDECEK et al., 2007). Porém, com o aumento da intensidade de preparo, a sobrevivência das mudas foi de até $91 \%$ no ER. Gatto et al. (2003) obtiveram $71,2 \%$ de sobrevivência para as plantas sob cultivo mínimo e $88,5 \%$ para o tratamento que recebeu queima, destoca e subsolagem. Finger et al. (1996) encontraram 97,62 \% de sobrevivência em solo subsolado e $92,86 \%$ em solo sem subsolagem. 
Assim, o estabelecimento e crescimento radicular e aéreo do eucalipto são favorecidos pelo revolvimento localizado do solo, o que pode reduzir os custos e aumentar a produtividade dos povoamentos florestais.

\section{CONCLUSÕES}

Os sistemas de manejo escarificado, escarificado com gradagem e enxada rotativa promovem a redução da resistência à penetração e da densidade do solo até a profundidade de $0,30 \mathrm{~m}$.

A análise da distribuição radicular no perfil, apesar de ser um método qualitativo, é eficiente em demonstrar o efeito do preparo do solo para implantação do Eucalyptus grandis.

As mudas de eucalipto plantadas sob o preparo com enxada rotativa apresentam maior crescimento em diâmetro e altura, enquanto que $o$ menor crescimento é obtido no plantio direto.

$\mathrm{O}$ efeito da escarificação sobre as propriedades físicas do solo persistem após um ano da mobilização de um Argissolo com textura franco-arenosa.

\section{REFERÊNCIAS BIBLIOGRÁFICAS}

BENGHOUGH, A. G. et al. Root responses to soil physical conditions; growth dynamics from field to cell. Journal of Experimental Botany, v. 57, n. 2, p. 437-447, Sept. 2006.

BÖHM, W. Methods of studying root systems. Berlin: Springer-Verlag Berlin Heidelberg, 1979. $190 \mathrm{p}$.

BUSSCHER, W.J. Adjustment of $\mathrm{fl}$ attipped penetrometer resistance data to a common water content. Transactions of American Society Agricultural Engineering, v. 33, p. 519-524, Mar./ Apr. 1990.

CAVICHIOLO, S. R. et al. Modificações nos atributos físicos de solos submetidos a dois sistemas de preparo em rebrota de Eucalyptus saligna. Revista Árvore, Viçosa, v. 29, n. 4, p. 571-577, jul./ ago. 2005.

CLEMENTE, E. P. et al. Soil compaction around Eucalyptus grandis roots: a micromorphological study. Australian Journal of Soil Research. v. 43, n. 2, 139-146, Mar. 2005.

COLLARES, G. L. et al. Qualidade física do solo na produtividade da cultura do feijoeiro num Argissolo. Pesquisa Agropecuária Brasileira. Brasília, v. 41, n. 11, p. 1663-1674, nov. 2006.
DEDECEK, R. A. et al. Efeitos de sistemas de preparo do solo na erosão e na produtividade da acácia-negra (Acacia mearnsii De Wild). Ciência Florestal, Santa Maria, v. 17, n. 3, p. 205-215, jul./ set. 2007.

EMBRAPA. Manual de métodos de análise de solo. 2. ed. Rio de Janeiro: Centro Nacional de Pesquisa de Solos, 1997. 212 p.

EMBRAPA. Sistema brasileiro de classificação de solos. 2. ed. Rio de Janeiro: Centro Nacional de Pesquisa de Solos, 2006. 306 p.

FINGER, C. A. G. et al. Influência da camada de impedimento no solo sobre o crescimento de Eucalyptus grandis (Hill) ex Maiden. Ciência Florestal, Santa Maria, v. 6, n. 1, p. 137-145, jan./ mar. 1996.

GATTO, A. et al. Efeito do método de preparo do solo, em área de reforma, nas suas características, na composição mineral e na produtividade de plantações de Eucalyptus grandis. Revista Árvore, Viçosa, v. 27, n. 5, p. 1-15, set./out. 2003. GAVA, J. L. et al. Soil attributes and Wood quality for pulp production in plantations of Eucalyptus grandis clone. Scientia Agrícola. v. 65, n. 3, p. 306313, maio/jun. 2008.

GERARD, C. J. et al. Physical factors influencing soil strength and root growth. Agronomy Journal, v. 74, p. 875-879, Sept./Oct. 1982.

GONÇALVES, J. L. M. Principais solos usados para plantações florestais. In: GONÇALVES, J. L. M.; STAPE, J. L. Conservação e cultivo de solos para plantações florestais. Piracicaba: IPEF, 2002, cap. 1, p.1-46.

HAMZA, M. A.; ANDERSON, W. K. Soil compaction in cropping systems: A review of the nature, causes and possible solutions. Soil \& Tillage Research, v. 82, n. 2, p.121-145,June 2005.

LAMPURLANÉS, J. et al. Soil bulk density and penetration resistance under different tillage and crop management systems and their relationship with barley root growth. Agronomy Journal, v. 95, p. 526-536, May/June 2003.

LIMA et al. Densidade crítica ao crescimento de plantas considerando água disponível e resistência à penetração de um Argissolo Vermelho distrófico arênico. Ciência Rural, v. 37, n. 4, p. 1166-1169, jul/ago, 2007.

MALUF, L. L. P. Efeito da queima, métodos de preparo do solo e da adubação no crescimento de Eucalyptus camaldulensis em Areia Quartzosa. 1991. 78 p. Dissertação (Mestrado em Solos e Nutrição de Plantas) - Universidade Federal 
de Viçosa, Viçosa, 1991.

MARTINS, S. G. et al. Avaliação de atributos físicos de um Latossolo Vermelho distroférrico sob diferentes povoamentos florestais. Cerne, Lavras, v. 8, n. 1, p. 32-41, jan./abr. 2002.

MISRA, R. K; GIBBONS, A. K. Growth and morphology of eucalypt seedling-roots, in relation to soil strength from compaction. Plant and Soil, Netherlands, v. 182, n. 1, p.1-11, May 1996.

MORENO, J. A. Clima do Rio Grande do Sul. Porto Alegre: Secretaria da Agricultura, 1961. 42 p. PAIXÃO, F. A. et al. Quantificação do estoque de carbono e avaliação econômica de diferentes alternativas de manejo em um plantio de eucalipto. Revista Árvore, v. 30, n. 3, p. 411-420, maio/jun. 2006.

PIERCE, F. J. et al. Immediate and residual effects of zone tillage in rotation with no-tillage on soil physical properties and corn performance. Soil \& Tillage Research, v. 24, n. 2, p. 149-165, July 1992.

PRADO, R. de M. et al. Sistemas de preparo e resistência à penetração e densidade de um Latossolo Vermelho eutrófico em cultivo intensivo e pousio. Pesquisa Agropecuária Brasileira, v. 37, n. 12, p. 1795-1801, dez. 2002.

REICHERT, J. M. et al. Compactação do solo em sistemas agropecuários e florestais: identificação, efeitos, limites críticos e mitigação. In: CERRETA, C. A.; SILVA, L. S. da; REICHERT, J. M. (Ed.). Tópicos em ciência do solo. Viçosa: Sociedade Brasileira de Ciência do Solo, 2007. v.5. p.49-134. REICHERT, J. M. et al. Reference bulk density and critical degree-of compactness for no-till crop production in subtropical highly weathered soils. Soil \& Tillage Research, v.102, n. 2, p.242254, Mar. 2009b.

REICHERT, J. M. et al. Variação temporal de propriedades físicas do solo e crescimento radicular de feijoeiro em quatro sistemas de manejo.
Pesquisa Agropecuária Brasileira. Brasília, v. 44, n. 3, p. 310-319, mar. 2009a.

SAS INSTITUTE. Getting started with the SAS learning edition. Cary: SAS, 2002. 200 p.

SILVA, V. R. et al. Fatores controladores da compressibilidade de um Argissolo Vermelho Amarelo distrófico arênico e de um Latossolo Vermelho distrófico típico. I - Estado inicial de compactação. Revista Brasileira de Ciência do Solo, v. 26, n. 1, p. 1-8, jan./abr. 2002.

SOCIEDADE BRASILEIRA DE SILVICULTURA. Fatos e números do Brasil florestal, 2008. Disponível em: <http://www.sbs.org.br/ FatoseNumerosdoBrasilFlorestal.pdf $>$. Acesso em: 27 julho de 2010.

STAPE, J. L. et al. Definição de métodos de preparo do solo para silvicultura em solos coesos do litoral norte da Bahia. In: GONÇALVES, J. L. M.; STAPE, J. L. Conservação e cultivo de solos para plantações florestais. Piracicaba: IPEF, 2002, cap. 7, p. 259-296.

SUZUKI, L. E. A. S. Compactação do solo e sua influência nas propriedades físicas do solo e crescimento e rendimento de culturas. 2005. 151 f. Dissertação (Mestrado em Ciência do Solo) Universidade Federal de Santa Maria, Santa Maria, 2005.

TAYLOR, H. M. et al. Soil strength-root penetration relations of coarse textured materials. Soil Science, Baltimore, v. 102, n. 1, p. 18-22, July 1966.

TORMENA, C. A. et al. Densidade, porosidade e resistência à penetração em latossolo cultivado sob diferentes sistemas de preparo do solo. Scientia Agricola. Piracicaba, v.59, n.4, p.795-801, out./dez. 2002.

WHITMAN, A. A.; BROKAW, V. L.; HAGAN, J. $M$. Forest damage caused by logging of mahogany (Swietenia macrophylla) in northern Belize. Forest Ecology and Management, Amsterdan, v. 92, p. 87-96, 1997. 